\title{
Combined action of estrogen receptor agonists and antagonists in two-hybrid recombinant yeast in vitro
}

\author{
Rong Yang, Na Li, Kaifeng Rao, Mei Ma*, Zijian Wang *** \\ Key Laboratory of Drinking Water Science and Technology, Research Center for Eco-Environmental Sciences, \\ Chinese Academy of Sciences, Beijing 100085, PR China
}

\section{A R T I C L E I N F O}

\section{Article history:}

Received 14 May 2014

Received in revised form

21 September 2014

Accepted 23 September 2014

Available online 31 October 2014

\section{Keywords:}

Mixture toxicity

Antiestrogen

Estrogen

Prediction model

Two-hybrid yeast bioassay

\begin{abstract}
A B S T R A C T
Estrogen receptor (ER) antagonistic chemicals in aquatic environments are believed to influence the binding of both endogenous and exogenous estrogens to ERs in aquatic organisms. Although the combined effects of estrogenic compounds have attracted much scientific concern, little work has been done on the influence of such antiestrogens on the biological effects of estrogens. This study focused on how the presence of different amounts of antagonists affects the results of ER agonist activity tests. To achieve this, three questions were stated and answered in sequence. A two-hybrid recombinant yeast assay mediated by ER was adopted, providing a single mode of action and single target of action for this study. Mixtures created by an ER agonist and three antagonists following the fixed-ratio principle were assessed. The concentration of $17 \beta$-estradiol causing maximum induction was set as the fixed dose of estrogen in the antagonist activity test (question 1). When the two classes of chemicals coexisted, antiestrogens, which as a whole behaved according to the concentration addition model (question 2), decreased the response of estrogen and compressed the concentration-response curves along the $y$-axis in the agonist activity test (question 3). This may cause the estradiol equivalent to be underestimated and potentially mask the action of estrogenic effects in toxicity evaluation of environmental samples.

(c) 2014 Elsevier Inc. All rights reserved.
\end{abstract}

\section{Introduction}

Among the various endocrine disrupting chemicals (EDCs) in aquatic environments, the estrogen-disrupting chemicals are the topic of most EDC mixture researches (Sharpe and Irvine, 2004). They include the estrogen-mimicking chemicals that simulate the physiological behavior of natural hormones, antiestrogens that antagonize the estrogenic effect in a variety of ways, and chemicals with different actions in various tissues, such as the selective estrogen receptor modulators (SERMs). All of them are released to the environment via

\footnotetext{
Abbreviations: CA, concentration addition; DMSO, dimethyl sulfoxide; E2, 17 $\beta-$ estradiol; $\mathrm{EC}_{50}$, half maximal effective concentration; $\mathrm{EC}_{\text {submax }}$, sub-maximal effective concentration; EDCs, endocrine disrupting chemicals; ER, estrogen receptor; FUL, fulvestrant; $\mathrm{HCH}, \gamma$-hexachlorocyclohexane; MoA, mode of action; OECD, Organization for Economic Co-operation and Development; OHT, 4-hydroxytamoxifen; OHT-EQ tamoxifen equivalent; ONPG, 0 -nitrophenyl- $\beta$-D-galactopyranoside; RA, response addition; REP, relative potency; SERM, selective estrogen receptor modulator; ToA, target of action; USEPA, U.S. Environmental Protection Agency; USDHHS, U.S. Department of Health and Human Services.

* Correspondence to: Key Laboratory of Drinking Water Science and Technology, Research Center for Eco-Environmental Sciences, Chinese Academy of Sciences, Beijing 100085, PR China. Tel./fax: +861062849141.

** Correspondence to: Key Laboratory of Drinking Water Science and Technology, Research Center for Eco-Environmental Sciences, Chinese Academy of Sciences, Beijing 100085, PR China, Tel./fax: +86 1062849140.

E-mail addresses: mamei@rcees.ac.cn (M. Ma), wangzj@rcees.ac.cn (Z. Wang).
}

different sources and are presented simultaneously instead of separately. Thus, these chemicals not only have adverse effects on organisms at very low-level exposure (Myers et al., 2009), but also have the potential of additive or even synergistic effects when acting in combination (Kunz and Fent, 2006; Sun et al., 2009).

Estrogenic chemicals have been the focus of many studies for a long time. Most of these studies are based on two classic models, concentration addition (CA) and response addition (RA) (USEPA, 2000). The CA model assumes that all mixture components act on the same molecular site competitively and cause the same response (Loewe, 1928). In contrast, when all components behave independently and do not affect or alter the other components' toxicity, the RA model is the better choice (Bliss, 1939). In most scenarios of the mixture toxicity of estrogens, CA has been considered to describe the effects well, with the test organisms covering not only yeast and single cells, but also higher levels of complexity such as rodents and fish (Brian et al., 2005; Payne et al., 2001; Ramamoorthy et al., 1997; Silva et al., 2002). However, compared with the large number of studies on estrogenic chemicals, the joint effects of estrogens and antiestrogens have been less reported. This is probably because they belong to different classes of EDCs (Kortenkamp, 2007): estrogens exert their influence through their interactions with many enzymes and biomacromolecules, while antiestrogens inhibit the estrogenic effect by disrupting or even blocking these interactions. 
Most studies on the combined effects of estrogen and antiestrogen mixtures have been conducted by exposing organisms to increasing concentrations of antiestrogen with a certain dose of estrogen (Petersen and Tollefsen, 2012; Sun et al., 2011). This kind of experimental design can be used to evaluate the efficacy of antiestrogenic drugs by describing how they decrease the response to a constant amount of an estrogen in organisms, but it cannot reflect the characteristics of the environmental samples. In a water sample where both estrogens and antiestrogens coexist, the doses of all chemicals change in proportion during the concentration and dilution processes. It is quite different from the former situation, thus we investigated this scenario.

The objective of this study was to evaluate the deviation of estrogenicity when antiestrogens are present in a sample by answering three questions: (1) for an untested antiestrogen, how do we choose the fixed concentration of the model estrogen for the antagonistic activity test? (2) For a combination of antiestrogens, which model should be applied to predict the combined effects well, CA or RA? (3) For a mixture containing $x$ estrogens and $y$ antiestrogens, does and if so how does the presence of antiestrogens affect the bioassay results of estrogens when the fixed-ratio design is adopted? Among the various modes of action (MoAs) of estrogen-disrupting chemicals, the estrogen receptor (ER) binding capacity plays a significant role, because it is the basis for many estrogen screening bioassays in real environmental applications. Therefore, the ER-mediated production of $\beta$-galactosidase in two-hybrid recombinant yeast was used here to offer a single MoA (binding to ER) and a single target of action (ToA, ER) (Li et al., 2008b; Sheeler et al., 2000). One estrogen and three antiestrogens - referred to as ER agonist and antagonists were selected for mixture preparation, including an endogenous estrogen, two drugs for breast cancer therapy, and one ER antagonistic pesticide.

\section{Materials and methods}

\subsection{Chemicals}

17 $\beta$-estradiol (E2, 97\%), 4-hydroxy-tamoxifen (OHT, 98\%), fulvestrant (FUL, 98\%) and dimethyl sulfoxide (DMSO, 99.5\%) were purchased from Sigma-Aldrich (St Louis, MO, USA). $\gamma$-hexachlorocyclohexane $(\mathrm{HCH}, 99.3 \%)$ was purchased from AccuStandard Incorporation (New Haven, CT, USA). All test chemicals were dissolved in DMSO to make the standard solutions and stored at $-20^{\circ} \mathrm{C}$.

\subsection{Experimental design}

We selected one estrogen (E2) and three antiestrogens (OHT, FUL and $\mathrm{HCH}$ ) to create the mixtures used in this study (see Table 1). All test chemicals dissolved well and were stable in the solvent, and their concentrations did not change during the 2-h exposure. Thus, we believe the actual and nominal concentrations should be in good agreement with each other.

A series of three experiments was designed according to questions 1-3: an antagonist activity test for single antiestrogens with varying E2 concentrations, an antagonist activity test for antiestrogenic mixtures, and an agonist activity test for estrogen plus antiestrogen mixtures. DMSO was used in the dilution process and served as a co-solvent in the individual chemical and the mixture tests. Its final concentration was set to $0.5 \%$ in exposure cultures, which does not cause any cytotoxicity in yeast cells.

First, according to the E2 concentration-response curve, three concentration levels were chosen as the fixed estrogen concentration for the antagonistic activity measurement: $\mathrm{EC}_{50}, \mathrm{EC}_{\text {submax }}$ (which causes the sub-maximum response, also used as the positive control) and $2 \times \mathrm{EC}_{\text {submax }}$. Seven decreasing concentrations of both OHT and FUL were obtained by double dilution, and their effects were separately assessed based on the different levels of E2.

Then, four mixtures of antiestrogens including three binary mixtures (M1-M3) and a tertiary mixture (M4) were designed using the equivalent effect principle (Table 2), which means that all concentrations of components in a mixture were set to cause equal effects based on the antiestrogenic activity of each chemical. The concentration-response sigmoid curve of every mixture was obtained by testing seven concentration gradients of the fixedratio combination with the co-exposure of E2 at the level of $\mathrm{EC}_{\text {submax }}$

Finally, mixtures containing both estrogens and antiestrogens were created, and the assay was conducted without the presence of E2 at a constant concentration. The relationships between estrogens and antiestrogens were arranged in the order of oneto-one and one-to-many. For one estrogen and one antiestrogen, three ratios - $\mathrm{EC}_{50}(\mathrm{E} 2): \mathrm{EC}_{50}(\mathrm{OHT}), 2 \times \mathrm{EC}_{50}(\mathrm{E} 2): \mathrm{EC}_{50}(\mathrm{OHT})$ and $\mathrm{EC}_{50}(\mathrm{E} 2): 2 \times \mathrm{EC}_{50}(\mathrm{OHT})$ - were set, which were recorded as $1: 1$, 2:1 and 1:2 (group I). For multiple antiestrogens, the concept of tamoxifen equivalent (OHT-EQ) was introduced to describe the total antagonistic effect. The concentration ratio was arranged by imitating group I, where the combination of OHT and FUL (group II) was used to replace OHT alone. Every antiestrogen was designed to cause an even antagonistic effect and to keep the total OHT-EQ unchanged (details in Table 3).

\subsection{Bioassay}

The modern theory of ligand-receptor interaction was established based on the discovery of coactivators in 1990s (Hong et al., 1996). The ligand-binding domain of ER contributes to the dimerization interface with estrogens, and a conformational change of the ligand-receptor complex occurs. The complex recruits a coactivator(s) and finally leads to the transcription and translation of downstream target gene. This is the theoretical basis of the twohybrid yeast assay, which we conducted according to Li et al. (2008a), and all samples were assayed in quadruplicate. After overnight growth at $30{ }^{\circ} \mathrm{C}$ with shaking at $130 \mathrm{rpm}$, the yeast optical density at $600 \mathrm{~nm}$ was adjusted to 0.75 , to ensure that the strain was in the logarithmic phase. When determining the estrogenic activity, $5 \mu \mathrm{L}$ of control or dilution of single or mixed stock solutions of test substances were mixed with $995 \mu \mathrm{L}$ of synthetic dextrose medium containing approximately $5 \times 10^{3}$ yeast cells per $\mathrm{mL}$. The antagonistic activity of samples was measured by co-incubation of yeast cells with the positive control $\left(5 \times 10^{-8} \mathrm{~mol} / \mathrm{L} \mathrm{E} 2\right.$ in DMSO or $2.5 \times 10^{-10} \mathrm{~mol} / \mathrm{L} \mathrm{E} 2$ in exposure culture), which can produce a sub-maximum induction response. Two hundred milliliters of control/test culture were added to each well of a 96-well plate (Corning, Tewksbury, MA, USA). Then, a 2-h exposure at $30^{\circ} \mathrm{C}$ was started with vigorous orbital shaking $(800 \mathrm{rpm})$ on a titer plate shaker (Heidolph TITRAMAX 1000, Hamburg, Germany), to prevent yeast cells from precipitating, which was followed by a measurement of the cultures' absorbance at $600 \mathrm{~nm}$ (TECAN GENios A-5002, Salzburg, Austria). To lyse yeast cells and release the endoenzyme, $\beta$-galactosidase, $150 \mu \mathrm{L}$ of test culture were removed, and the remaining culture was carefully mixed with $120 \mu \mathrm{L}$ of Z-buffer $\left(16.1 \mathrm{~g} / \mathrm{L} \mathrm{Na}_{2} \mathrm{HPO}_{4} \cdot 7 \mathrm{H}_{2} \mathrm{O}, 5.5 \mathrm{~g} / \mathrm{L}\right.$ $\left.\mathrm{NaH}_{2} \mathrm{PO}_{4} \cdot \mathrm{H}_{2} \mathrm{O}, 0.75 \mathrm{~g} / \mathrm{L} \mathrm{KCl}, 0.246 \mathrm{~g} / \mathrm{L} \mathrm{MgSO} \mathrm{Mg}_{4} \cdot 7 \mathrm{H}_{2} \mathrm{O}\right)$ and $20 \mu \mathrm{L}$ of chloroform at $30{ }^{\circ} \mathrm{C}$ and $1300 \mathrm{rpm}$ for $10 \mathrm{~min}$. Then, $40 \mu \mathrm{L}$ of $o$-nitrophenyl- $\beta$-D-galactopyranoside (ONPG, $13.3 \mathrm{mmol} / \mathrm{L}$ in Z-buffer) were added to initiate the enzymatic reaction. After incubation at $30{ }^{\circ} \mathrm{C}$ for $60 \mathrm{~min}$, the reaction was terminated by adding $100 \mu \mathrm{L}$ of $\mathrm{Na}_{2} \mathrm{CO}_{3(\mathrm{aq})}(1 \mathrm{~mol} / \mathrm{L})$. To prevent the influence of 
Table 1

Information and characteristics of concentration-response relationships of individual compounds.

\begin{tabular}{|c|c|c|c|c|c|c|c|c|c|c|}
\hline \multirow[t]{2}{*}{ Group } & \multicolumn{4}{|c|}{ Information } & \multicolumn{4}{|c|}{ Fitting parameter } & \multicolumn{2}{|c|}{ Regression result } \\
\hline & Abbr. ${ }^{a}$ & Name & CAS & MW & $a$ & $b$ & $x_{0}$ & $y_{0}$ & $\mathrm{EC}_{50}$ & REP \\
\hline Estrogen & E2 & $17 \beta$-estradiol & $50-28-2$ & 272.39 & 106.0969 & -2.9914 & 6.7297E-11 & -4.3392 & $6.73 \mathrm{E}-11$ & 1.00 \\
\hline \multirow[t]{3}{*}{ Antiestrogen } & OHT & 4-Hydroxytamoxifen & $68392-35-8$ & 387.51 & 99.8780 & -1.4745 & $4.7103 \mathrm{E}-7$ & -0.0121 & $4.71 \mathrm{E}-7$ & 1.00 \\
\hline & FUL & fulvestrant & $129453-61-8$ & 606.77 & 94.6611 & -2.3868 & $4.0263 \mathrm{E}-7$ & 0.8193 & $4.03 \mathrm{E}-7$ & 1.17 \\
\hline & $\mathrm{HCH}$ & $\gamma$-Hexachlorocyclohexane & $58-89-9$ & 290.83 & 98.0058 & -1.9484 & $4.6005 \mathrm{E}-5$ & 0.1849 & $4.60 \mathrm{E}-5$ & $1.02 \mathrm{E}-2$ \\
\hline
\end{tabular}

${ }^{a}$ Abbr.=abbreviation; $\mathrm{CAS}=$ the chemical abstract services registry number; $\mathrm{MW}=$ molecular weight $(\mathrm{g} / \mathrm{mol}) ; \mathrm{EC}_{50}=\mathrm{half}$ maximal effective concentration $(\mathrm{mol} / \mathrm{L}$ ); $\mathrm{REP}=$ relative potency, $\mathrm{REP}(i)=\mathrm{EC}_{50}(\mathrm{E} 2$ or $\mathrm{OHT}) / \mathrm{EC}_{50}(i)$.

Table 2

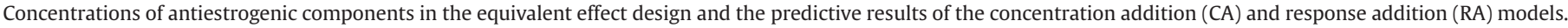

\begin{tabular}{|c|c|c|c|c|c|c|c|}
\hline \multirow[t]{2}{*}{$N_{\text {test }}{ }^{\mathrm{a}}$} & \multirow[t]{2}{*}{ Test no. } & \multicolumn{3}{|c|}{ Composition and concentration } & \multicolumn{3}{|l|}{$\mathrm{EC}_{50}$} \\
\hline & & $\mathrm{OHT}$ & FUL & $\mathrm{HCH}$ & Obs. & CA & RA \\
\hline \multirow[t]{3}{*}{3} & M1 & $2.50 \mathrm{E}-6$ & $2.14 \mathrm{E}-6$ & - & $(4.63 \pm 0.20) \mathrm{E}-7$ & $4.71 \mathrm{E}-7$ & $6.11 \mathrm{E}-7$ \\
\hline & M2 & $2.50 \mathrm{E}-6$ & - & $2.45 \mathrm{E}-4$ & $(3.97 \pm 0.47) \mathrm{E}-7$ & $4.71 \mathrm{E}-7$ & $5.76 \mathrm{E}-7$ \\
\hline & M3 & - & $2.14 \mathrm{E}-6$ & $2.45 \mathrm{E}-4$ & $(5.44 \pm 0.99) \mathrm{E}-7$ & $4.71 \mathrm{E}-7$ & $6.42 \mathrm{E}-7$ \\
\hline 4 & M4 & 1.67E-6 & $1.43 \mathrm{E}-6$ & $1.64 \mathrm{E}-4$ & $(4.66 \pm 0.40) \mathrm{E}-7$ & $4.71 \mathrm{E}-7$ & $7.11 \mathrm{E}-7$ \\
\hline
\end{tabular}

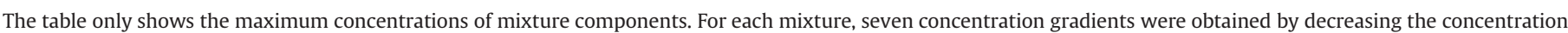
by a factor of two.

${ }^{\text {a }} N_{\text {test }}=$ number of test chemicals in mixture; Obs.=observation, mean \pm standard deviation; $C A=$ concentration addition; RA=response addition; unit: mol/L.

Table 3

Fixed-ratio design and the estrogenicity of test mixtures containing both estrogens and antiestrogens.

\begin{tabular}{|c|c|c|c|c|c|c|c|}
\hline \multirow[t]{2}{*}{ Group } & \multirow[t]{2}{*}{ Test no. } & \multirow[t]{2}{*}{ Toxicity ratio $^{a}$} & \multirow{2}{*}{$\frac{\text { Estrogen }^{\mathrm{b}}}{\mathrm{E} 2}$} & \multicolumn{2}{|c|}{ Antiestrogen $^{\mathrm{b}}$} & \multirow[t]{2}{*}{$\mathrm{EC}_{50}{ }^{\mathrm{c}}$} & \multirow[t]{2}{*}{ Maximal induction ratio ${ }^{\mathrm{d}}$} \\
\hline & & & & OHT & FUL & & \\
\hline \multirow[t]{3}{*}{ I } & 1 & $1: 1$ & $4.80 \mathrm{E}-10$ & $3.36 \mathrm{E}-6$ & - & $(6.26 \pm 0.44) \mathrm{E}-11$ & $46.95 \pm 3.17$ \\
\hline & 2 & $2: 1$ & $9.60 \mathrm{E}-10$ & $3.36 \mathrm{E}-6$ & - & $(5.03 \pm 0.50) \mathrm{E}-11$ & $66.15 \pm 5.13$ \\
\hline & 3 & $1: 2$ & $4.80 \mathrm{E}-10$ & $6.72 \mathrm{E}-6$ & - & $(7.76 \pm 1.52) \mathrm{E}-11$ & $30.53 \pm 3.93$ \\
\hline \multirow[t]{5}{*}{ II } & 1 & $1: 1(1: 1)$ & $4.80 \mathrm{E}-10$ & $1.68 \mathrm{E}-6$ & $1.44 \mathrm{E}-6$ & $(5.77 \pm 0.24) \mathrm{E}-11$ & $54.32 \pm 1.85$ \\
\hline & 2 & $2: 1(1: 1)$ & $9.60 \mathrm{E}-10$ & $1.68 \mathrm{E}-6$ & $1.44 \mathrm{E}-6$ & $(5.72 \pm 0.57) \mathrm{E}-11$ & $68.85 \pm 5.26$ \\
\hline & 3 & $1: 2(1: 1)$ & $4.80 \mathrm{E}-10$ & $3.36 \mathrm{E}-6$ & $2.87 \mathrm{E}-6$ & $(7.30 \pm 0.78) \mathrm{E}-11$ & $31.27 \pm 2.57$ \\
\hline & 4 & $1: 1(2: 1)$ & $4.80 \mathrm{E}-10$ & $2.24 \mathrm{E}-6$ & $9.57 \mathrm{E}-7$ & $(6.95 \pm 0.40) \mathrm{E}-11$ & $51.29 \pm 2.28$ \\
\hline & 5 & $1: 1(1: 2)$ & $4.80 \mathrm{E}-10$ & $1.12 \mathrm{E}-6$ & $1.91 \mathrm{E}-6$ & $(6.08 \pm 0.16) \mathrm{E}-11$ & $49.71 \pm 0.97$ \\
\hline
\end{tabular}

As in Table 2, this table shows the maximum concentrations of chemical components.

${ }^{a}$ Toxicity ratio is the ratio of E2 to OHT (or OHT-EQ), and numbers in brackets refer to the mixing proportion of antiestrogens if more than one are present.

${ }^{\mathrm{b}}$ Unit: $\mathrm{mol} / \mathrm{L}$.

c Unit: $\mathrm{mol} / \mathrm{L}$, mean \pm standard deviation.

${ }^{\mathrm{d}}$ Unit: \%, mean \pm standard deviation.

viscous cell fragments at the bottom of the wells, $200 \mu \mathrm{L}$ of the supernatant were transferred into a new plate and the absorbance at $420 \mathrm{~nm}$ was measured.

The $\beta$-galactosidase activity was calculated as follows:

$U=\left(\mathrm{OD}_{420} \mathrm{~s}-\mathrm{OD}_{420} b\right) \times D /\left(t \times V \times \mathrm{OD}_{600}\right)$,

where $U$ is the $\beta$-galactosidase activity; $\mathrm{OD}_{420} S$ and $\mathrm{OD}_{420} b$ are the absorbance of the supernatant of the sample and the negative control (DMSO) at $420 \mathrm{~nm}$, respectively; $\mathrm{OD}_{600}$ is the absorbance of the test culture at $600 \mathrm{~nm}$, and $t, V$ and $D$ are the constants indicating the incubation duration of the enzymatic reaction, the volume of the test culture, and the dilution factor, respectively.

To normalize the $\beta$-galactosidase activity, the agonistic and antagonistic activity of the samples tested are expressed by the degree that the $\beta$-galactosidase activity was induced or inhibited as calculated by the following equations:

Induction ratio $\%=U_{s} / U_{p} \times 100$,

Inhibition ratio $\%=\left(1-U_{s} / U_{p}\right) \times 100$.

Here, $U_{s}$ and $U_{p}$ are the enzyme activity stimulated by the test sample and positive control, respectively. Sigmaplot 11.0 software (SPSS Inc., Chicago, IL, USA) was used for data processing.

In addition, the cytotoxicity was measured to ensure that the change in enzymatic activity was truly caused by agonistic/ antagonistic responses and not by the influence of yeast death. Cytotoxicity was determined spectrophotometrically as the change in $\mathrm{OD}_{600}$ (reflects cell density) of the culture medium after exposure. 


\subsection{Statistical analysis of single chemicals}

According to the scatter plots of the induction/inhibition ratio and $\log$ concentration, the concentration-response curves of single chemicals were obtained, which fitted well with the logistic function:

Logistic function : $E=y_{0}+\frac{a}{1+\left(x / x_{0}\right)^{|b|}}$,

Inverse logistic function : $x=x_{0} \sqrt[|b|]{\left[a /\left(E-y_{0}\right)\right]-1}$,

where $E$ and $x$ indicate the induced or inhibited effect in this assay and the chemical concentration tested, respectively, and $a, b, x_{0}$ and $y_{0}$ are the parameters with different meaning.

The relative potencies (REPs) of estrogen and antiestrogen represent the agonistic and antagonistic effects of chemicals relative to those of E2 and OHT, respectively. They were calculated by simply using the $\mathrm{EC}_{50}$ values.

\subsection{Mathematical prediction of mixture toxicity}

To predict the combined effects of intraclass chemicals (e.g., OHT and FUL), the two widely accepted CA and RA models were used. It has been reported that the predictions of the two appear very similar, while the MoA of components remains unclear (Huang et al., 2011). In this study, CA was appropriate for the two-hybrid yeast system; however, RA was also applied to assess its performance under the single MoA circumstance. Their predictive powers were evaluated by comparing the results of a model calculation and an experimental observation. CA is commonly expressed as follows:

$\mathrm{EC} x_{\text {mix }}=\left(\sum_{i=1}^{n}\left(p_{i} / \mathrm{EC} x_{i}\right)\right)^{-1}$,

where $\mathrm{EC} x_{\text {mix }}$ and $\mathrm{EC} x_{i}$ are the concentrations of the mixture and the $i$ th component causing effect $x$, respectively, and $p_{i}$ is the concentration of component $i$ (Backhaus et al., 2000).

The prediction obtained by the RA model is as follows:

$E\left(c_{m i x}\right)=1-\prod_{i=1}^{n}\left(1-E\left(c_{i}\right)\right)$,

a

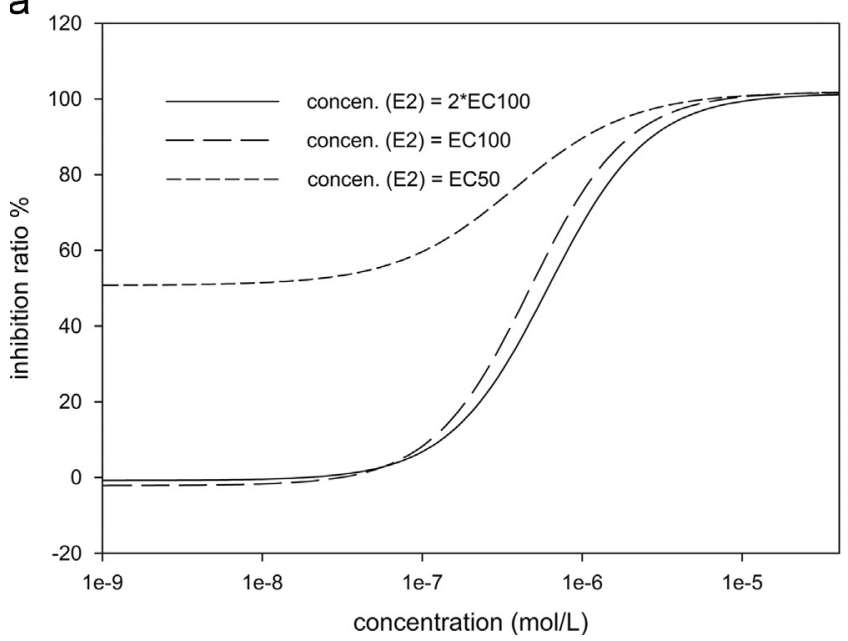

where $c_{\text {mix }}$ and $c_{i}$ are the sum of the concentrations of all components and the $i$ th component, respectively, and $E\left(c_{\text {mix }}\right)$ and $E\left(c_{i}\right)$ represent their effects (Faust et al., 2003).

For calculation convenience, we used the OHT-EQ concept derived from CA, to get the overall antagonist activity of mixtures containing more than one antiestrogen:

$\mathrm{OHT}-\mathrm{EQ}=\sum_{i=1}^{n}\left(c_{i} \times \mathrm{REP}_{i}\right)$

where $c_{i}$ and $\mathrm{REP}_{i}$ are the concentration and the REP value of the $i$ th mixture component, respectively.

For interclass chemicals (E2 and OHT, or E2 and OHT-EQ), comparisons were made between the inducing effects driven by the model estrogen only and mixtures that also contained different amounts of antiestrogens. By examining the change in $\mathrm{EC}_{50}$ and maximum effect levels of the sigmoid curves, the influence of antiestrogen was assessed.

\section{Results}

\subsection{Individual chemical exposure}

A concentration-dependent increase in $\beta$-galactosidase activity was observed when yeast were exposed to E2 alone, while co-exposure to E2 with the maximum effect and any of the three antiestrogens showed decreased enzymatic activity. The relationships between the log concentration and induction/inhibition ratio can be well described by the logistic regression model (Eq. 4), as all the coefficients of determination $\left(R^{2}\right)$ were greater than 0.99. All antiestrogen regression curves were basically parallel, and the same was true for the antiestrogen curves (data not shown). The fitting parameters and regression results are listed in Table 1. OHT and FUL displayed almost the same effect, while the potency of $\mathrm{HCH}$ was approximately 100 -fold weaker.

The four test chemicals did not affect the survival or proliferation of yeast, whether acting alone or co-exposed with $2.5 \times$ $10^{-10} \mathrm{~mol} / \mathrm{L}$ E2 (data not shown), suggesting that these chemicals are not cytotoxic in the selected concentration range.

\subsection{Effect of different E2 concentrations}

The antagonistic effects of the two ER downregulators OHT and FUL were separately tested while the concentration of E2 was fixed

b

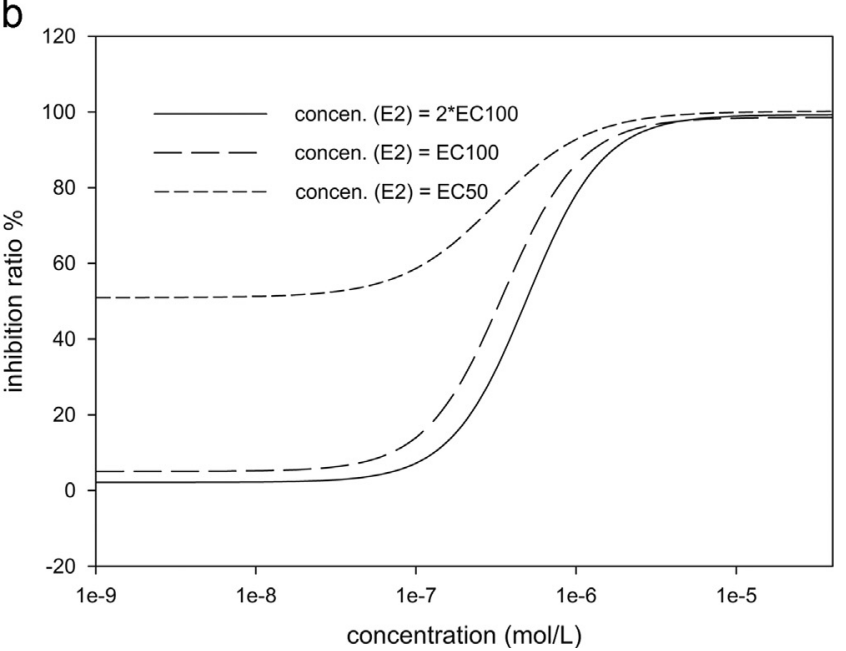

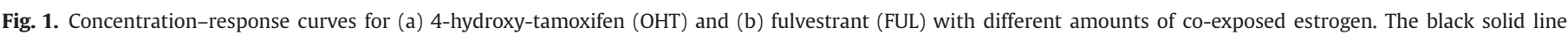

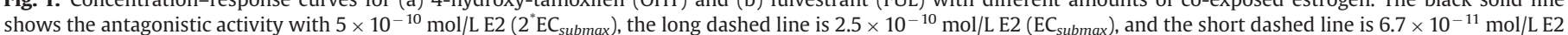
$\left(\mathrm{EC}_{50}\right)$. 

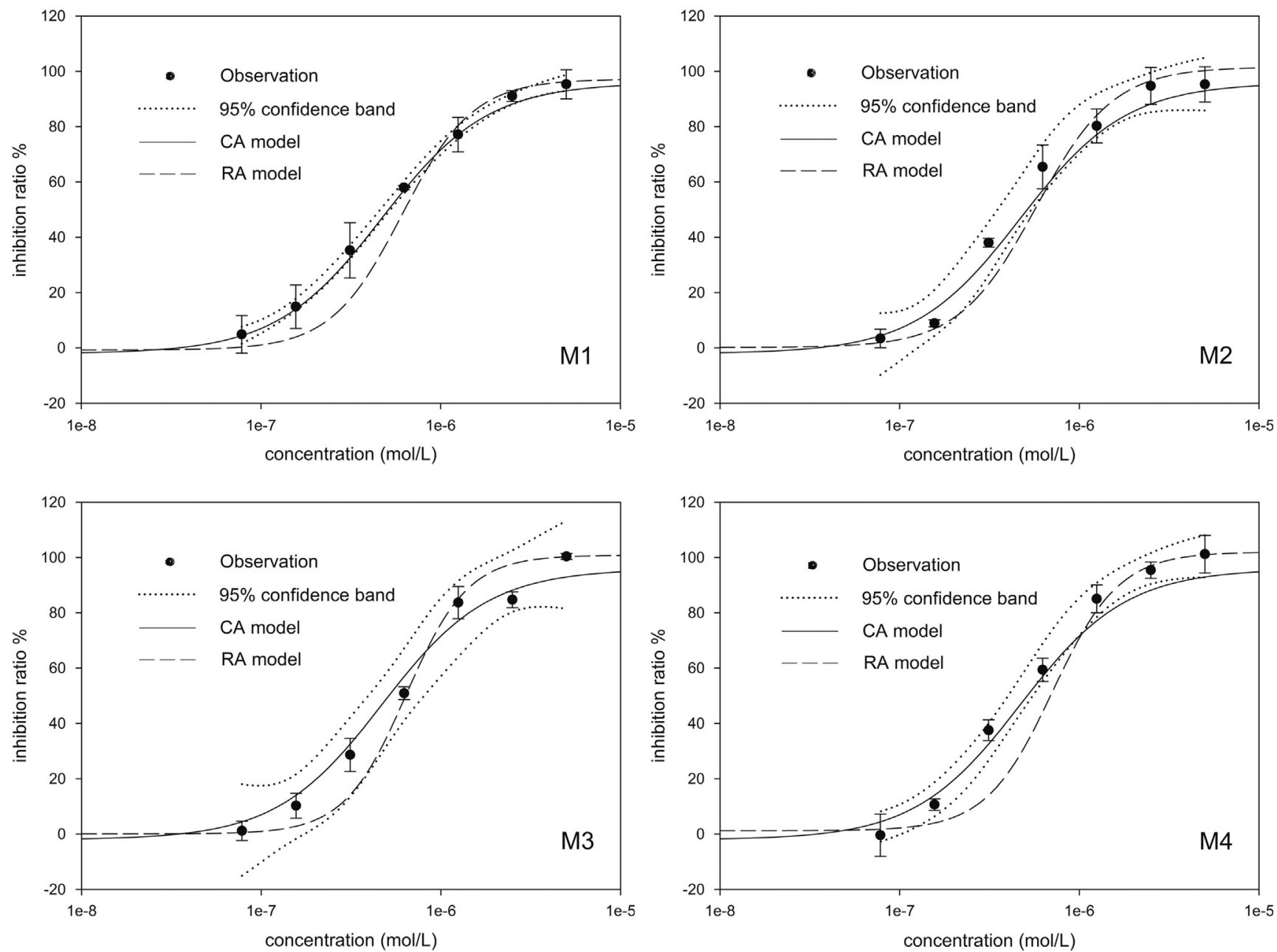

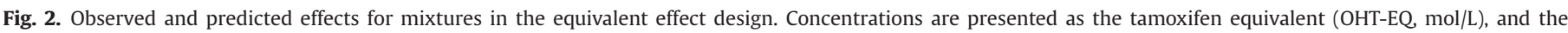

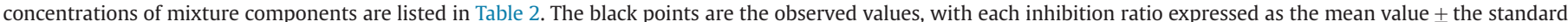

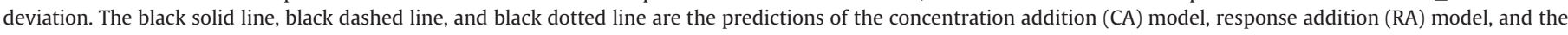
$95 \%$ confidence band of observation, respectively.

to different levels. Their $\mathrm{EC}_{50}$ values tended to increase with the increasing E2 concentration (Fig. 1). As the dose of E2 increased from $\mathrm{EC}_{50}$ (short dashed line) to $\mathrm{EC}_{\text {submax }}$ (long dashed line) and $2 \times \mathrm{EC}_{\text {submax }}$ (solid line), the $\mathrm{EC}_{50}$ of $\mathrm{OHT}$ changed from $3.76 \times 10^{-7}$ to $4.71 \times 10^{-7}$ and $6.15 \times 10^{-7} \mathrm{~mol} / \mathrm{L}$, and that of FUL changed from $3.12 \times 10^{-7}$ to $4.03 \times 10^{-7}$ and $4.94 \times 10^{-7} \mathrm{~mol} / \mathrm{L}$, respectively.

\subsection{Combined effect of antiestrogens in antagonistic activity tests}

According to the $\mathrm{EC}_{50} \mathrm{~S}$ and REPs of the three antiestrogens, they were combined at equipotent concentrations to create four different mixtures. Two non-interaction models, CA and RA, were applied to predict the combined antagonistic effects, and their results were compared with the bioassay observations. According to Fig. 2, where all mixtures had significant inhibiting effects on $\beta$-galactosidase production (black points), CA (black solid line) was always between the two 95\% confidence bands of observation (black dotted line), while RA (black dashed line) was not. According to the $\mathrm{EC}_{50}$, the prediction results of $\mathrm{CA}\left(4.71 \times 10^{-7}\right.$ $\mathrm{mol} / \mathrm{L})$ were closer to the measured values $\left(3.97 \times 10^{-7}\right.$ $\left.5.44 \times 10^{-7} \mathrm{~mol} / \mathrm{L}\right)$ than those of RA $\left(5.76 \times 10^{-7}-7.11 \times 10^{-7} \mathrm{~mol} / \mathrm{L}\right)$, indicating that under the single MoA circumstance, CA is a more appropriate predictor.

\subsection{Toxicity of mixtures containing both estrogen and antiestrogen}

When only E2 and OHT were mixed in three different ratios related to their $\mathrm{EC}_{50} \mathrm{~S}$ (group I in Table 3, recorded as MI-1-MI-3), these mixtures showed different concentration-dependent induction manners (Fig. 3a). They shared the same $\mathrm{EC}_{50}$ values with $\mathrm{E} 2$, but they had variable maximum induction ratios. When the mixing proportion of $\mathrm{E} 2$ and $\mathrm{OHT}$ equaled $\mathrm{EC}_{50}(\mathrm{E} 2): \mathrm{EC}_{50}(\mathrm{OHT})$ $(1: 1, \mathrm{MI}-1)$, the maximum induction ratio was very close to $50 \%$, which changed to $66 \%$ and $31 \%$ when the mixing proportions were $2 \times \mathrm{EC}_{50}(\mathrm{E} 2): \mathrm{EC}_{50}(\mathrm{OHT})(2: 1, \mathrm{MI}-2)$ and $\mathrm{EC}_{50}(\mathrm{E} 2): 2 \times \mathrm{EC}_{50}(\mathrm{OHT})$ (1:2, MI-3), respectively. This demonstrated that increasing the proportion of OHT (I-2 to I-1 to I-3) decreased the maximum induction ratio of the concentration-response curve (66\% to $50 \%$ to $31 \%$ of pure E2), and that an empirical equation could be obtained from the bioassay data: when the proportion between E2 and OHT is $m \mathrm{EC}_{50}(\mathrm{E} 2): n \mathrm{EC}_{50}(\mathrm{OHT})$

Maximum induction ratio $(\mathrm{mix}) \%=m /(m+n) \times 100$.

When OHT was replaced by a mixture of OHT and FUL, no matter how the proportion of the two changed (MII-1, MII-4 and MII-5 in Fig. 3b), their effect on estrogens could be judged with reference to the results of Group I by studying the ratio of E2 to OHT-EQ instead of OHT itself. When the ratios were set to be the same as MI-1-MI-3, the concentration-response curves exactly 
a

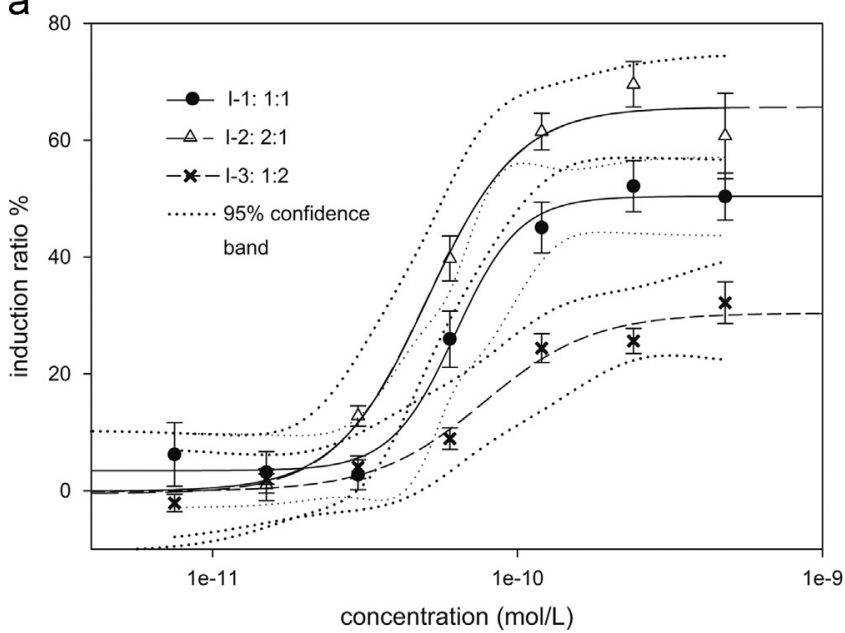

b

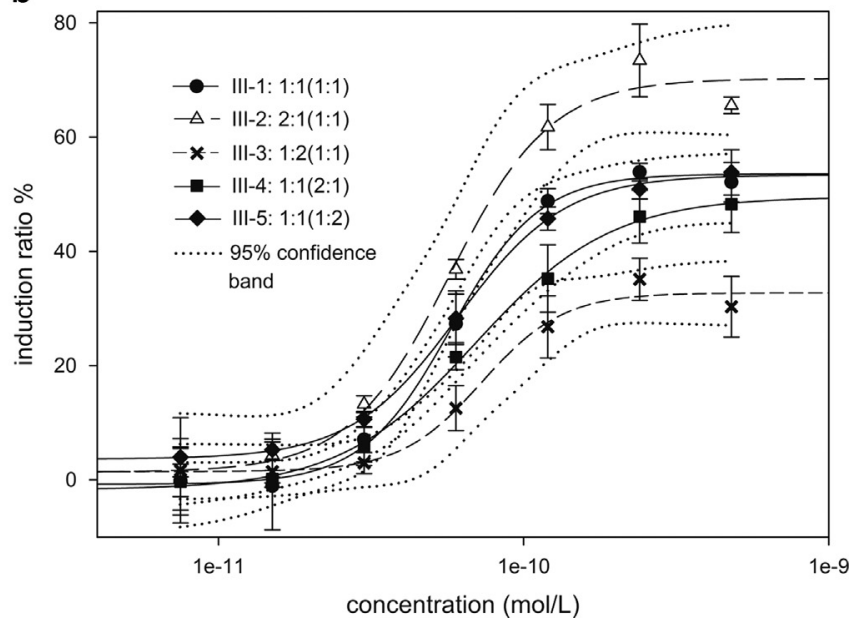

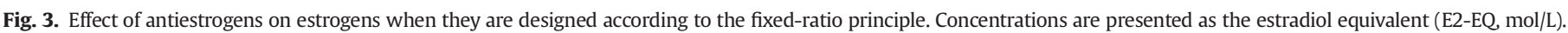
(a) $17 \beta$-estradiol (E2) and OHT, group I in Table 3 and (b) E2 and two antiestrogens, group II. The corresponding toxicity ratios are also shown in the legend as $x$ : $y$ ( $m: n$ ).

coincided with Fig. 3a (MII-1-MII-3 in Fig. 3b). Thus, if the proportion between $\mathrm{E} 2$ and $\mathrm{OHT}-\mathrm{EQ}$ is $\mathrm{mEC}_{50}(\mathrm{E} 2): n \mathrm{EC}_{50}(\mathrm{OHT})$, the maximum induction ratio of the mixture can be calculated using Eq. (9), which is not limited to the scenario of one estrogen and one antiestrogen.

\section{Discussion}

Recently, many institutions and organizations, including the U.S. Environmental Protection Agency (USEPA), the Department of Health and Human Services (USDHHS), and the Organization for Economic Co-operation and Development (OECD) have developed bioassay lists for estrogenic activity detection (OECD, 2012; USDHHS, 2013; USEPA, 2013). They cover the rapid, economic and high-throughput in vitro tests and the in vivo tests, which provide complicated and detailed interaction information in the body. However, for environmental applications, the in vitro tests are preferred (Buckley, 2010; Conroy et al., 2007; García-Reyero et al., 2001; Kusk et al., 2011; Vega-López et al., 2007; Zhao et al., 2011), and most of them are based on or related to the ER, suggesting the important role it plays in the function of estrogens. Therefore, the current study only focused on the ER agonist and antagonist activities of estrogen-disrupting chemicals, ignoring disruptions of other related processes such as the biological synthesis, transportation and elimination of hormones.

In this study, E2 was selected to represent the main contributors to estrogenicity in the aquatic environment. As a natural hormone secreted by living organisms, E2 is widely distributed in water systems and has strong estrogenic effects (Duong et al., 2010; Jiang et al., 2012). It showed strong affinity to ER, with an $\mathrm{EC}_{50}$ value of $6.73 \times 10^{-11} \mathrm{~mol} / \mathrm{L}$, which was lower than most of the reported values (Rouhani Rankouhi et al., 2005; Salste et al., 2007; Van den Belt et al., 2004). In contrast, there is no list of typical antiestrogens, so we chose three chemicals from two classes of model antagonists and relevant environmental pollutants. OHT and FUL are used as common medicine for ER-positive breast cancer treatment and are released through the urine and feces of patients undergoing drug therapy (Brauch et al., 2009; Robertson, 2001). HCH (also called Lindane) is a pesticide that is used on a large scale with a high detection rate and concentration, and has been reported to have antiestrogenic activity (Li et al., 2008a). All of these ER downregulators appeared to have the ability to competitively bind to receptors in the presence of a certain amount of E2, but their potencies differed. Here, the former two showed similar strong antiestrogenicity with an $\mathrm{EC}_{50}$ of $4.71 \times 10^{-7}$ and $4.03 \times 10^{-7} \mathrm{~mol} / \mathrm{L}$, respectively, which is consistent with the report that they had similar treatment efficacies in breast cancer (Howell et al., 2004). HCH performed as a weak ER antagonist in the recombinant yeast $\left(\mathrm{EC}_{50}=4.60 \times 10^{-5} \mathrm{~mol} / \mathrm{L}\right)$, although both its estrogenic and antiestrogenic activities have been observed in other organisms (Briz et al., 2011; Chadwick et al., 1988; Huang et al., 2006; Raizada et al., 1980).

Because the binding of an antiestrogen to ER cannot initiate the expression of the reporter gene lac- $Z$, the inhibition effect test had to be executed by simultaneously exposing the yeast cells to E2 and the tested antagonist. Then, choosing an appropriate concentration of E2 became an issue. To understand whether different concentrations lead to different results, the antiestrogenicity tests of OHT and FUL were conducted with three concentrations of E2: $\mathrm{EC}_{50}, \mathrm{EC}_{\text {submax }}$ and twice the value of $\mathrm{EC}_{\text {submax }}$. We found that with the increasing concentration of $\mathrm{E} 2$, the antagonistic effect of the antiestrogens decreased. This is because a higher concentration of E2 increases the possibility of collision and binding of E2 to ER, and decreases the chance of collision and binding of OHT to ER. Thus, from the perspective of bioassay sensitivity, the $\mathrm{EC}_{50}$ concentration would be the preferred concentration. However, considering that less E2 can reduce the response intensity and the signal-to-noise ratio of the test, we chose the $\mathrm{EC}_{\text {submax }}$ concentration of E2 to achieve a compromise effect, and this choice was applied in all the antagonistic activity tests in this study. The concentration causing the sub-maximum effect has been used by many researchers in the antagonist tests (Bovee et al., 2008; Kolle et al., 2010; Wang et al., 2005), as well as in previous studies by our lab (Li et al., 2008a; Li et al., 2010). Therefore, our selection of $\mathrm{EC}_{\text {submax }}$ is consistent with these studies and conducive for comparisons.

When multiple antiestrogens were mixed to result in a combined inhibiting effect, our analysis revealed that the CA model was an appropriate predictor of the mixture's toxicity regardless of the potencies, concentrations and compositions (OHT + FUL, $\mathrm{OHT}+\mathrm{HCH}$, FUL $+\mathrm{HCH}$, and $\mathrm{OHT}+\mathrm{FUL}+\mathrm{HCH}$ ), while the RA prediction was inaccurate. The result was logical, because the single receptor-ligand pathway in the recombinant yeast strain satisfied all of the CA model demands, but not the RA requirements. Although it has been reported that both CA and RA were useful predictors via single and multiple MoAs (yeast and breast cancer cells) (Payne et al., 2000, 2001), our data showed that for similarly 
acting chemicals the CA model is recommended for assessing mixtures. Thus, in the next part of the study on estrogen plus antiestrogen mixtures, the CA-derived standard chemical equivalent approach was applied to describe the ER agonist/antagonist effects of the whole mixture. Analogous to the toxic equivalent concept with Ah-receptor binding chemicals (Van den Berg et al., 1998), OHT-EQ was obtained from the definition equation of CA. It is more convenient for assessing real samples, because it simplifies the calculation process. Furthermore, it was demonstrated as a good predictor of the combined effects. However, this conclusion cannot be applied to all scenarios, especially if other MoAs are involved. For example, Zhao et al. (2006) have reported deviations from the CA and RA models by testing mixtures of two antiestrogens and using vitellogenin as a biomarker. Petersen and Tollefsen (2012) assessed antiestrogenic mixtures containing up to 11 components, and found a similar phenomenon. These findings indicate the influence of different antiestrogenic mechanisms.

In the real world, antiestrogens are mixed with estrogenic chemicals rather than existing in isolation. Investigating the effects of sole inhibitors cannot reflect the natural exposure situation. Instead, chemicals from both classes should be combined. According to Fig. 3, the antiestrogens decreased the induction ratios, without changing the $\mathrm{EC}_{50} \mathrm{~S}$ of the concentration-response curves. This is because the dynamic interaction between ligands and receptors includes association, dissociation and recombination (Carroll et al., 2012; Hughes et al., 2012). The binding probability of a certain ligand depends on its proportion in the ligands cocktail. As an example in our study, when ERs were exposed to an $\mathrm{E} 2+\mathrm{OHT}$ mixture with a ratio of $m \mathrm{EC}_{50}(\mathrm{E} 2): n \mathrm{EC}_{50}(\mathrm{OHT})$, only $m /$ $(m+n)$ of ERs could bind to E2 and initiate the reporter gene expression, while the rest could not because they remained unbound or bound to OHT. Hence, for this mixture the estrogenic response reduced to $m /(m+n)$ of its original level at every concentration of E2, making the curve become "shorter". Therefore, the compression along the $y$-axis decreased the induction ratio, but the $\mathrm{EC}_{50}$ remained the same. These explanations are the basis for the empirical equation, Eq. (9). When a sample containing estrogen and antiestrogen is obtained, there are countless ratios at which they may be mixed. Therefore, we need to establish a rule to extrapolate any other possible compositions from the three typical ratios we studied. Thus, for a complicated mixture, first the amount of E2 and OHT-EQ should be determined separately. Then, we can predict the degree of inhibition by Eq. (9), which is only dependent on the efficacy ratio of the estrogens and antiestrogens.

\section{Conclusions}

In this study, we found that in the two-hybrid recombinant yeast bioassay, (1) an appropriate concentration of a positive compound helps maintain the high sensitivity and response intensity of the antagonistic activity test; (2) the effects of antiestrogenic mixtures can be predicted by the CA model and the derived OHT-EQ concept; and (3) the presence of antiestrogens decreases the response to estrogen, causing misestimation of the estrogen quantity. Compared with estrogens, the number of studies on antiestrogens is very limited. For the two standard ER antagonists in this study, even fewer studies have reported their concentrations in aquatic environments (Negreira et al., 2013). Although we examined the antiestrogens as a whole and described them using OHT-EQ instead of focusing on their specific kind and concentration, determining the main antiestrogenic contributors and their identification, monitoring and control are also important.

This work was conducted at the molecular level. At this level, antiestrogens may render the results of nuclear receptor-based and related bioassays imprecise. We found that the actions of estrogens and antiestrogens could not be set off against each other by simple addition or subtraction. At higher levels, such as the cell, organ and individual levels, where other MoAs must be taken into account, the problem becomes more complicated. For instance, antiestrogens no longer act additively; instead, they act antagonistically or synergistically (Petersen and Tollefsen, 2012; Zhao et al., 2006). In the future, we predict that the combined action of ER agonists and antagonists in vivo will receive more interest and concern; hence we need an improved model with more parameters and correction factors to reflect the sophisticated physiological changes in individual organisms.

\section{Conflict of interest}

The authors declare that they have no conflict of interest.

\section{Acknowledgments}

We wish to express thanks to the National Natural Science Foundation of China (Grant no. NSFC 51290283), the National High Technology Research and Development Program of China (2014AA06A506) and the "One-Three-Five" Strategic Planning of Chinese Academy of Sciences (YSW2013A02) for their financial supports.

\section{References}

Backhaus, T., Scholze, M., Grimme, L.H., 2000. The single substance and mixture toxicity of quinolones to the bioluminescent bacterium Vibrio fischeri. Aquat. Toxicol. 49, 49-61.

Bliss, C.I., 1939. The toxicity of poisons applied jointly. Ann. Appl. Biol. 26, 585-615. Bovee, T.F.H., Schoonen, W.G.E.J., Hamers, A.R.M., Bento, M.J., Peijnenburg, Ad A.C.M., 2008. Screening of synthetic and plant-derived compounds for (anti)estrogenic and (anti)androgenic activities. Anal. Bioanal. Chem. 390, 1111-1119.

Brauch, H., Mürdter, T.E., Eichelbaum, M., Schwab, M., 2009. Pharmacogenomics of tamoxifen therapy. Clin. Chem. 55, 1770-1782.

Brian, J.V., Harris, C.A., Scholze, M., Backhaus, T., Booy, P., Lamoree, M., Pojana, G. Jonkers, N., Runnalls, T., Bonfà, A., Marcomini, A., Sumpter, J.P., 2005. Accurate prediction of the response of freshwater fish to a mixture of estrogenic chemicals. Environ. Health Perspect. 113, 721-728.

Briz, V., Molina-Molina, J.M., Sánchez-Redondo, S., Fernández, M.F., Grimalt, J.O., Olea, N., Rodríguez-Farré, E., Suñol, C., 2011. Differential estrogenic effects of the persistent organochlorine pesticides dieldrin, endosulfan, and lindane in primary neuronal cultures. Toxicol. Sci. 120, 413-427.

Buckley, J.A., 2010. Quantifying the antiestrogen activity of wastewater treatment plant effluent using the yeast estrogen screen. Environ. Toxicol. Chem. 29, 73-78.

Carroll, M.J., Mauldin, R.V., Gromova, A.V., Singleton, S.F., Collins, E.J., Lee, A.L., 2012. Evidence for dynamics in proteins as a mechanism for ligand dissociation. Nat. Chem. Biol. 8, 246-252.

Chadwick, R.W., Cooper, R.L., Rehnberg, G.L., McElroy, W.K., Chang, J., 1988. Possible antiestrogenic activity of lindane in female rats. J. Biochem. Toxicol. 3, 147-158.

Conroy, O., Sáez, A.E., Quanrud, D., Ela, W., Arnold, R.G., 2007. Changes in estrogen/ anti-estrogen activities in ponded secondary effluent. Sci. Total Environ. 382, $311-323$.

Duong, C.N., Ra, J.S., Cho, J., Kim, S.D., Choi, H.K., Park, J.H., Kim, K.W., Inam, E., Kim, S.D. 2010. Estrogenic chemicals and estrogenicity in river waters of South Korea and seven Asian countries. Chemosphere 78, 286-293.

Faust, M., Altenburger, R., Backhaus, T., Blanck, H., Boedeker, W., Gramatica, P., Hamer, V., Scholze, M., Vighi, M., Grimme, L.H., 2003. Joint algal toxicity of 16 dissimilarly acting chemicals is predictable by the concept of independent action. Aquat. Toxicol. 63, 43-63.

García-Reyero, N., Grau, E., Castillo, M., De Alda, M.J.L., Barceló, D., Piña, B., 2001 Monitoring of endocrine disruptors in surface waters by the yeast recombinant assay. Environ. Toxicol. Chem. 20, 1152-1158.

Hong, H., Kohli, K., Trivedi, A., Johnson, D.L., Stallcup, M.R., 1996. GRIP1, a novel mouse protein that serves as a transcriptional coactivator in yeast for the hormone binding domains of steroid receptors. Proc. Natl. Acad. Sci. 93 4948-4952.

Howell, A., Robertson, J.F.R., Abram, P., Lichinitser, M.R., Elledge, R., Bajetta, E. Watanabe, T. Morris, C., Webster, A., Dimery, I., Osborne, C.K., 2004. Comparison of fulvestrant versus tamoxifen for the treatment of advanced breast cancer in postmenopausal women previously untreated with endocrine therapy: a multinational, double-blind, randomized trial. J. Clin. Oncol. 22, 1605-1613. 
Huang, D.J., Chen, H.C., Wu, J.P., Wang, S.Y., 2006. Reproduction obstacles for the female green neon shrimp (Neocaridina denticulata) after exposure to chlordane and lindane. Chemosphere 64, 11-16.

Huang, W.Y., Liu, F., Liu, S.S., Ge, H.L., Chen, H.H., 2011. Predicting mixture toxicity of seven phenolic compounds with similar and dissimilar action mechanisms to Vibrio qinghaiensis sp. nov. 067. Ecotoxicol. Environ. Saf. 74, 1600-1606.

Hughes, T.S., Chalmers, M.J., Novick, S., Kuruvilla, D.S., Chang, M.R., Kamenecka, T.M., Rance, M., Johnson, B.A., Burris, T.P., Griffin, P.R., Kojetin, D.J., 2012. Ligand and receptor dynamics contribute to the mechanism of graded PPAR $\gamma$ agonism. Structure 20, 139-150.

Jiang, W.W., Yan, Y., Ma, M., Wang, D.H., Luo, Q., Wang, Z.J., Satyanarayanan, S.K., 2012. Assessment of source water contamination by estrogenic disrupting compounds in China. J. Environ. Sci. 24, 320-328.

Kolle, S.N., Kamp, H.G., Huener, H.A., Knickel, J., Verlohner, A., Woitkowiak, C., Landsiedel, R., Van Ravenzwaay, B., 2010. In house validation of recombinant yeast estrogen and androgen receptor agonist and antagonist screening assays. Toxicol. in Vitro 24, 2030-2040.

Kortenkamp, A., 2007. Ten years of mixing cocktails: a review of combination effects of endocrine-disrupting chemicals. Environ. Health Perspect. 115, 98-105.

Kunz, P.Y., Fent, K., 2006. Estrogenic activity of UV filter mixtures. Toxicol. Appl. Pharmacol. 217, 86-99.

Kusk, K.O., Krüger, T., Long, M., Taxvig, C., Lykkesfeldt, A.E., Frederiksen, H. Andersson, A.M., Andersen, H.R., Hansen, K.M.S., Nellemann, C., BonefeldJørgensen, E.C., 2011. Endocrine potency of wastewater: contents of endocrine disrupting chemicals and effects measured by in vivo and in vitro assays. Environ. Toxicol. Chem. 30, 413-426.

Li, J., Li, N., Ma, M., Giesy, J.P., Wang, Z.J., 2008a. In vitro profiling of the endocrine disrupting potency of organochlorine pesticides. Toxicol. Lett. 183, 65-71.

Li, J., Ma, M., Rao, K.F., Wang, Z.J., 2008b. Construction the recombinant human estrogen receptor (hER) gene yeast using two-hybrid yeast technique. Asian J. Ecotoxicol. 3, 21-26.

Li, N., Wang, D.H., Zhou, Y.Q., Ma, M., Li, J., Wang, Z.J., 2010. Dibutyl phthalate contributes to the thyroid receptor antagonistic activity in drinking wate processes. Environ. Sci. Technol. 44, 6863-6868.

Loewe, S., 1928. Die quantitativen probleme der pharmarkologic. Ergeb. Physiol. 27 47-187.

Myers, J.P., Zoeller, R.T., Vom Saal, F.S., 2009. A clash of old and new scientific concepts in toxicity, with important implications for public health. Environ. Health Perspect. 117, 1652-1655.

Negreira, N., Mastroianni, N., De Alda, M.L., Barceló, D., 2013. Multianalyte determination of 24 cytostatics and metabolites by liquid chromatographyelectrospray-tandem mass spectrometry and study of their stability and optimum storage conditions in aqueous solution. Talanta 116, 290-299.

OECD, 2012. Detailed review paper on the state of the science on novel in vitro and in vivo screening and testing methods and endpoints for evaluating endocrine disruptors. Environment, Health and Safety Publications Series on Testing and Assessment. Joint Meeting of the Chemicals Committee and the Working Party on Chemicals, Pesticides and Biotechnology, Paris.

Ramamoorthy, K., Vyhlidal, C., Wang, F., Chen, I.C., Safe, S., McDonnell, D.P., Leonard, L.S Gaido, K.W., 1997. Additive estrogenic activities of a binary mixture of $2^{\prime}, 4^{\prime}, 6^{\prime}$ trichloro- and 2',3',4',5'-tetrachloro-4-biphenylol. Toxicol. Appl. Pharmacol. 147, 93-100.

Payne, J., Rajapakse, N., Wilkins, M., Kortenkamp, A., 2000. Prediction and assessment of the effects of mixtures of four xenoestrogens. Environ. Health Perspect. 108, 983-987.

Payne, J., Scholze, M., Kortenkamp, A., 2001. Mixtures of four organochlorines enhance human breast cancer cell proliferation. Environ. Health Perspect. 109 391-397.

Petersen, K., Tollefsen, K.E., 2012. Combined effects of oestrogen receptor antagonists on in vitro vitellogenesis. Aquat. Toxicol. 112, 46-53.
Raizada, R.B., Misra, P., Saxena, I., Datta, K.K., Dikshith, T.S.S., 1980. Weak estrogenic activity of lindane in rats. J. Toxicol. Environ. Health 6, 483-492.

Robertson, J.F.R., 2001. Faslodex (ICI 182, 780), a novel estrogen receptor downregulator-future possibilities in breast cancer. J. Steroid Biochem. Mol. Biol. 79, 209-212.

Rouhani Rankouhi, T., Sanderson, J.T., Van Holsteijn, I., Van Kooten, P., Bosveld, A.T.C., Van den Berg, M., 2005. Effects of environmental and natural estrogens on vitellogenin production in hepatocytes of the brown frog (Rana temporaria). Aquat. Toxicol. 71, 97-101.

Salste, L., Leskinen, P., Virta, M., Kronberg, L., 2007. Determination of estrogens and estrogenic activity in wastewater effluent by chemical analysis and the bioluminescent yeast assay. Sci. Total Environ. 378, 343-351.

Sharpe, R.M., Irvine, D.S., 2004. How strong is the evidence of a link between environmental chemicals and adverse effects on human reproductive health? Brit. Med. J. 328, 447-451.

Sheeler, C.Q., Dudley, M.W., Khan, S.A., 2000. Environmental estrogens induce transcriptionally active estrogen receptor dimers in yeast: activity potentiated by the coactivator RIP140. Environ. Health Perspect. 108, 97-103.

Silva, E., Rajapakse, N., Kortenkamp, A., 2002. Something from "nothing" - eight weak estrogenic chemicals combined at concentrations below NOECs produce significant mixture effects. Environ. Sci. Technol. 36, 1751-1756.

Sun, L.W., Shao, X.L., Hu, X.H., Chi, J., Jin, Y.X., Ye, W.H., Fu, Z.W., 2011. Transcriptional responses in Japanese medaka (Oryzias latipes) exposed to binary mixtures of an estrogen and anti-estrogens. Aquat. Toxicol. 105, 629-639.

Sun, L.W., Zha, J.M., Wang, Z.J., 2009. Interactions between estrogenic chemicals in binary mixtures investigated using vitellogenin induction and factorial analysis. Chemosphere 75, 410-415.

USDHHS, 2013. Endocrine disruptor test method evaluations. National Toxicology Program. 〈http://ntp.niehs.nih.gov/?objectid=2AEB14FF-C7EE-2B87-56896A27 CB856ED8> (accessed 04.04.14).

USEPA, 2000. Supplementary guidance for conducting health risk assessment of chemical mixtures. Risk Assessment Forum, Washington, D.C.

USEPA, 2013. OCSPP Harmonized Test Guidelines Series 890 - Endocrine Disruptor Screening Program Test Guidelines. Chemical Safety and Pollution Prevention. 〈http://www.epa.gov/ocspp/pubs/frs/publications/Test_Guidelines/series890. htm〉 (accessed 04.04.14).

Van den Belt, K., Berckmans, P., Vangenechten, C., Verheyen, R., Witters, H., 2004. Comparative study on the in vitro/in vivo estrogenic potencies of $17 \beta$-estradiol, estrone, 17 $\alpha$-ethynylestradiol and nonylphenol. Aquat. Toxicol. 66, 183-195.

Van den Berg, M., Birnbaum, L., Bosveld, A.T.C., Brunström, B., Cook, P., Feeley, M., Giesy, J.P., Hanberg, A., Hasegawa, R., Kennedy, S.W., Kubiak, T., Larsen, J.C., Van Leeuwen, F.X.R., Liem, A.K.D., Nolt, C., Peterson, R.E., Poellinger, L., Safe, S., Schrenk, D., Tillitt, D., Tysklind, M., Younes, M., Waern, F., Zacharewski, T., 1998. Toxic equivalency factors (TEFs) for PCBs, PCDDs, PCDFs for humans and wildlife. Environ. Health Perspect. 106, 775-792.

Vega-López, A., Ramón-Gallegos, E., Galar-Martínez, M., Jiménez-Orozco, F.A., García-Latorre, E., Domínguez-López, M.L., 2007. Estrogenic, anti-estrogenic and cytotoxic effects elicited by water from the type localities of the endangered goodeid fish Girardinichthys viviparus. Comp. Biochem. Physiol. C: Toxicol. Pharmacol. 145, 394-403.

Wang, J., Xie, P., Kettrup, A., Schramm, K.W., 2005. Inhibition of progesterone receptor activity in recombinant yeast by soot from fossil fuel combustion emissions and air particulate materials. Sci. Total Environ. 349, 120-128.

Zhao, B., Yang, J., Liu, Z.T., Xu, Z.F., Qiu, Y.P., Sheng, G.Y., 2006. Joint anti-estrogenic effects of PCP and TCDD in primary cultures of juvenile goldfish hepatocytes using vitellogenin as a biomarker. Chemosphere 65, 359-364.

Zhao, J.L., Ying, G.G., Yang, B., Liu, S., Zhou, L.J., Chen, Z.F., Lai, H.J., 2011. Screening of multiple hormonal activities in surface water and sediment from the Pearl River system, South China, using effect-directed in vitro bioassays. Environ. Toxicol. Chem. 30, 2208-2215. 